\title{
Los mandamientos virreinales en la formación del orden jurídico político de Nueva España, $1535-1595^{*}$
}

\author{
por Lara Semboloni
}

\begin{abstract}
This study is motivated by the obvious discrepancy between the official orders issued by institutions and the real mechanisms of negotiation and reproduction within the society of New Spain. The study covers the time within which most aspects of the colonial legal system and rule were installed, developed, and consolidated. The study tries to pinpoint the forms used by the viceroys to control the vast territories, and especially centers on the mandamientos as a key instrument in the formation and affirmation of governmental order, negotiated in a constant dialogue with all the political actors in the territory. The article analyzes the formal composition of mandamientos and provides a typology of different subsets and categories. Finally, it presents some results which were obtained by studying specific elements within the documents. For example, by studying the recipients of the mandamientos, one can see how certain political actors and charges lost in importance while others rised.
\end{abstract}

El móvil del presente trabajo es la inquietud por conocer las razones de la gran brecha entre lo que son, por un lado, los preceptos dictados por las instituciones americanas de gobierno y, por el otro, los mecanismos reales de reproducción y negociación en los ámbitos político, social, jurídico, etcétera, de las sociedades. Apoyada en la convicción de que la brecha tiene su raíz en el origen de la implantación del modelo político-jurídico colonial, la investigación gira en torno del origen de la institución virreinal y su universo de competencias y funciones a través de las acciones de gobierno. En este escrito, debido a necesidades editoriales, sólo se esboza el sustento teórico de tal postura, sin restar

* Este trabajo es un extracto de Lara Semboloni, La construcción de la autoridad virreinal en Nueva España, 1535-1595 (tesis doctoral, El Colegio de México 2007). 
importancia a las afirmaciones que se harán en seguida. El título del texto, que afirma que éste es un estudio acerca del "derecho novohispano", remite para esta definición al trabajo de la historiadora María del Refugio González, ${ }^{1}$ que aporta una completa bibliografía historiográfica acerca de los estudios teóricos de derecho indiano y la existencia del derecho provincial novohispano en una época de larga duración. El tema, que ha sido tratado las más de las veces por su significación para el conocimiento de los ámbitos jurídico y político de la sociedad novohispana en formación, ${ }^{2}$ tiene su propia relevancia en este trabajo para mostrar cómo, y con qué, se origina el citado derecho provincial, que irá definiendo la peculiaridad de Nueva España. Se abre, entonces, un abanico de posibilidades para investigaciones futuras porque si antes se constataba la existencia de fuentes de derecho factual, ahora se define una de las fuentes de este derecho.

Una vez definido el objeto de análisis, es importante subrayar el enfoque acerca del devenir histórico que representa el hilo conductor

1 María del Refugio González, El derecho indiano y el derecho provisional novohispano (México, D.F. 1995).

2 Victor Tau Anzoátegui, al referirse a los estudios de historia del derecho indiano, advirtió sobre "la inexistencia de estudios concretos sobre nuestro tema, ya en monografías, ya dentro de las obras generales". Aunque el derecho indiano tuvo como una de sus fuentes principales al "caso", tal como se ha visto líneas atrás, la mayor parte de los estudios que se han realizado hasta la fecha en torno a este tema sólo se han enfocado en el análisis de las "leyes" generales emitidas por los órganos superiores en España: el Consejo de Indias y el rey mismo. Es evidente que esto ha limitado mucho el conocimiento del derecho indiano en relación con la especificidad de un territorio y las características propias de la sociedad novohispana. (por "ley" se entiende una disposición dictada por una autoridad que posee la fuerza coercitiva). Victor Tau Anzoátegui, Casuismo y sistema (Buenos Aires 1992), p. 14.

Respecto a los estudios monográficos ver: Marcello Carmagnani, "El virrey y la corte virreinal en Nueva España. Una aproximación”: Francesca Cantú (ed.), Las cortes virreinales de la Monarquía española: América e Italia (Roma 2008), pp. 65-77. Existe la compilación de mandamientos de Peter Gerhard, Síntesis e índice de los mandamientos virreinales, 1548-1553 (México, D.F. 1992), que es un trabajo fundamental, pero no tiene un aparato crítico. Andrés Lira González, "La actividad jurisdiccional del virrey y el carácter judicial del gobierno Novohispano": Feliciano Barrios (coord.), El Gobierno de un mundo (Cuenca 2004), pp. 299-318, es un trabajo que abre muchas preguntas y donde se muestra cómo a través de la labor de gobierno de los primeros dos virreyes, estos actuaban dictando soluciones en materia jurisdiccional, creando precedentes jurídicos y que iban conformando el ámbito de autoridad del virrey en dialogo con las otras instancias del virreinato. Mi trabajo de tesis en su análisis cuantitativa confirma el resultado encontrado para la función jurisdiccional del virrey. 
para entender las afirmaciones aquí expresadas. El análisis histórico de un periodo tan extenso revela la existencia de rupturas en un proceso aparentemente gradual, y esas discontinuidades aportan elementos novedosos, cuando no francamente detonadores, en las ideas y creencias de una sociedad que finalmente son el producto de su historia. Esta afirmación, lejos de ser una disertación filosófica, representa la base de la certeza de que la sociedad del siglo XXI, aunque no refleja la del siglo XVI, es sin embargo su producto. Se sostiene lo anterior para marcar una distancia con aquellos historiadores que estudian la época moderna como "otro mundo", totalmente diferente y, por ende, desligado del contemporáneo; en contraste, el estudio de una sociedad en sus ámbitos jurídico y político siempre debe tener presente el origen de ambos.

El presente análisis parte del presupuesto teórico de que el virrey es la máxima institución de gobierno, responsable del orden político en Nueva España, y que la razón de ser de su institución, es decir, el derecho, ${ }^{3}$ garantiza un orden ${ }^{4}$ natural constituido por Dios y objetivado en una "constitución tradicional". ${ }^{5}$ Así, la función de gobierno no está desligada de la justicia, debido a la concepción moderna de gobierno en la época bajo estudio. Una vez sintetizados los presupuestos teóricos que funcionan como pegamento en este trabajo, se exponen a continuación algunas particularidades del estudio.

De acuerdo con todo el aparato teórico de los historiadores del derecho, la realidad de Nueva España en la primera mitad del siglo XVI carecía de órdenes sociales comparables a los europeos o, por lo menos, conocidos por los europeos; eran, más bien, relaciones gobernadas por ideas y creencias totalmente diferentes a las que el derecho incluyente "castellano" había acatado hasta aquel momento. El virrey no tenía que ser garante de un orden político; debía crearlo, en conjunto con las diferentes instituciones existentes en el ámbito territorial, y con el rey y su consejo. Uno de los instrumentos que revela de manera clara este fenómeno es el mandamiento - objeto de este trabajo. En este ensayo se busca sustentar, particularmente, el estudio del

3 Lira González, "La actividad jurisdiccional del virrey" (nota 2), pp. 299-318.

4 Para la definición de orden ver: António Manuel Espanha, História das instituições. Época Medieval e moderna (Coimbra 1982), p. 205; y Carlos Garriga, "Las Audiencias: Justicia y gobierno de las Indias": Barrios, El Gobierno de un mundo (nota 2), pp.711-793, aquí: p. 713.

5 Ibidem, p. 716. 
mandamiento en su función de acto productor de derecho y, por ende, se enfoca el análisis en la definición de este elemento y en sus tipificaciones, que permitirán en un segundo momento ofrecer interpretaciones para los fenómenos históricos.

Desde esta perspectiva, es fundamental la atención en la tipificación de las acciones de gobierno del virrey y sus alcances, en tanto productores de praxis. $^{6} \mathrm{La}$ investigación ha mostrado cómo se sentaron las bases jurídicas y se definieron las materias de competencia de la institución virreinal a través de las acciones cotidianas de los propios virreyes. Por otra parte, la incidencia y expansión que tuvieron las disposiciones del virrey en su calidad de gobernador durante la segunda mitad del siglo XVI jugaron un papel fundamental en la definición de los alcances de su actuación. Finalmente, esas disposiciones cotidianas, definidas como "mandamientos", han sido productoras de un derecho factual, "casuístico", 7 propio de la Nueva España, justamente lo que consideramos como "derecho novohispano".

Para adentrarse en el argumento, primero es necesario situar en contexto dos elementos básicos: a saber, 1) el intervalo temporal comprendido en el estudio y 2) la peculiaridad de la institución virreinal, que permite diferenciar el análisis del contexto (monárquico) europeo y, al mismo tiempo, considerar el caso indiano como "único".

1) La investigación considera las disposiciones del virrey como gobernador a partir de la llegada del primer virrey, don Antonio de Mendoza (1535), ${ }^{8}$ hasta la conclusión del primer mandato de don Luis

6 Acerca de la praxis jurídica novohispana ver: Javier Barrientos Grandon, La cultura jurídica en la Nueva España (México, D.F. 1993).

7 Respecto a la teoría del derecho y en particular modo al concepto de "casuismo", ver Tau Anzoátegui, Casuismo y sistema (nota 2); y Carlos Garriga, "Historia y derecho, historia del derecho": ISTOR IV, 16 (2004), pp. 3-8.

8 Se considera que el virrey Mendoza fue el primer virrey, en pleno sentido, a sabiendas de que el título formal de virrey por primera vez fue atribuido a Cristóbal Colón, pero que tal atribución del cargo a Colón y sucesivamente a su hijo, fue más un cargo honorífico que efectivo, como bien sostiene Rubio Mañé. En las capitulaciones que se firmaron en Santa Fe el 17 de abril de 1492 entre los Reyes Católicos y Cristóbal Colón, a este último, entre otras cosas, se le atribuyó el título de virrey. Pero después de pocos años se revocaron las funciones de gobierno, en mayo del 1499. Después de la muerte de Cristóbal Colón, a causa de una serie de acontecimientos en enero de 1515, la reina doña Juana designó Diego como "Almirante, Vissorey y Gobernador de la Isla Española”, hasta 1523, fecha en que murió. Cf. Ignacio Rubio Mañé, Introducción al estudio de los Virreyes de Nueva España 1535-1746, vol. 1: Origen y jurisdicción, y dinámica social de los virreyes (México, D. F. 1983), pp. 14-16. 
de Velasco hijo (1595), y propone identificar tres etapas diferentes en el desarrollo de la institución virreinal: instauración, transición y consolidación.

2) Los supuestos que fueron tomados en cuenta y que permiten identificar la especificidad del caso novohispano con respecto a los casos europeos, como la declaración del Consejo Real y Supremo de las Indias en 1524 y la validez de las disposiciones gubernativas del virrey. El Consejo Real define la relación entre los territorios indianos y la Corona de Castilla y, por ende, decide tanto el tipo de derecho aplicable en este territorio como el tipo de gobierno que se tiene que instaurar. Se dice que las Indias

"[...] se gobiernan por las leyes, derechos, i fuero de castilla, i se juzgan i tienen por una misma corona. Lo cual no sucede asi en los Reinos de Aragón, Nápoles, Sicilia, i Portugal, i Estados de Milan, Flandes i otros que se unieron y agregaron quedándose en el ser que tenian o como los Doctores dicen AEQue PRINCIPALITER. Porque en tal caso cada una se juzga por diversos i conserva sus leyes i privilegios". ${ }^{9}$

\section{Como afirma Barrientos Grandon:}

“[...] por el descubrimiento y una serie de otros títulos las islas y tierra firme del Mar Océano quedaron incorporadas a la corona de Castilla por accessio y no aeque principaliter, lo cual significaba que quedaban sujetas a la jurisdicción de un mismo príncipe". ${ }^{10}$

Así que la unión por accessio vinculaba jurisdiccionalmente al Nuevo Mundo con la Corona de Castilla y, por ende, el curso de la jurisdicción real en las Indias estaría, ab origo, ligado al de la propia Corona castellana, que, además, lo tuvo por modelo para su diseño. Se puede entonces afirmar que esta definición del tipo de relación con el territorio, hecha por el Consejo de Indias, revela la excepcionalidad de la situación, sin parangón en el pasado inmediato. La peculiaridad novohispana nace de la comparación con las competencias y funciones de los virreyes en territorio europeo. Mientras que en las Américas el virrey cuenta, en su función de gobernante de la Corona, con el apoyo

9 Juan Solórzano y Pereira, Memorial y discurso de las razones que se ofrecen para que el Real i Supremo consejo de las Indias deba preceder en todos los actos públicos al que llaman de Flandres, en Madrid por Francisco Martínez, 1629, XI, nota 66, fs. 20v-21r. Cf. Javier Barrientos Grandon, "El Cursus de la Jurisdicción Letradas en Las Indias (s. XVIXVII)": Barrios, El Gobierno de un mundo (nota 2), pp. 633-708, 683-686 y 688.

10 Javier Barriendo Grandon, Historia del derecho indiano del descubrimiento colombino a la codificación (Roma 2000), cap. 2, pp. 95-124. 
de asesores, ${ }^{11}$ sus acciones de gobierno tienen que ser recopiladas en "libros de gobierno" y no tienen término de validez en el tiempo. Por su parte, en el Virreinato de Cerdeña, por ejemplo, se estipula que la validez de las disposiciones gubernativas del virrey está sujeta a la presencia de la firma del regente de la Real Cancillería, además de la del virrey, así como la del abogado fiscal y, en el caso de que estos documentos únicamente hubieran sido firmados por el virrey y su secretario, mantenían su vigencia sólo durante el tiempo que permaneciera en su cargo. ${ }^{12}$ Esta particularidad del caso bajo estudio permite intuir ya la importancia de las disposiciones emitidas por el virrey en los nuevos territorios, tal como ha sido señalado por diferentes historiadores. ${ }^{13}$

El presente trabajo está enfocado en la definición del "derecho novohispano". Muestra algunos de los elementos que han permitido caracterizarlo y propone los lineamientos que han conducido a tal afirmación. Hablar de un "derecho novohispano" abre por un lado muchas vetas de investigación y por el otro se inserta en un debate de gran alcance. Además significa caracterizar y definir una realidad diferente a lo que ha sido considerado tradicionalmente como "Las Indias" y, por tanto, significa también afirmar que es posible acometer su análisis mismo, más allá de la existencia de varios tipos de praxis en los vastísimos territorios que han sido gobernados por la Monarquía hispánica. Si bien toda la historiografía apunta en este sentido y está demostrada la peculiaridad de cada región - sean éstas virreinatos, gobernaciones, capitanías, etc. -, la importancia de la investigación radica en demostrar que las diferencias surgen a partir de la instauración de la Monarquía española y que éstas se pueden identificar de manera clara con patrones que permiten su sistematización, lo que arroja como resultado la caracterización de tales diferencias. El tra-

${ }^{11}$ Marcello Carmagnani aporta un estudio acerca de la corte virreinal. Aunque en mi trabajo no he podido confirmar esta postura, podemos atender a este estudio, en donde se afirma que el mecanismo que permite al virrey implementar su función política de vinculación constante con los cuerpos del reino es la función de consejo. En efecto, el virrey debe tomar auxilium et consilium para asegurar el buen gobierno. Carmagnani, El virrey y la corte virreinal (nota 2).

12 Josefina Mateu Ibars, Los virreyes de Cerdeña, tomo I: 1410-1623 (Padova 1964), p. 59.

${ }^{13}$ Tau Anzoátegui, Casuismo y sistema (nota 2); Andrés Lira "La actividad jurisdiccional del virrey y el carácter judicial del gobierno novohispano en su fase formativa": Barrios, El Gobierno de un Mundo (nota 2), pp. 299-318; Gerhard, Síntesis e índice (nota 2), entre otros. 
bajo muestra que es posible el estudio de las acciones de gobierno del virrey considerando que éstas generan documentos formales que se insertan en la esfera jurídica y nos hacen ver la formación del derecho novohispano en un complejo de diversos ámbitos ${ }^{14}$ de autoridad.

\section{LA AUTORIDAD VIRREINAL COMO FUENTE PRODUCTORA DEL DERECHO}

El virrey en Nueva España se convierte en alter ego del rey y desempeña un amplio espectro de facultades, entre las que se encuentra la gobernación de Nueva España, que abarca diferentes ámbitos de funciones en un territorio en expansión. La importancia que reviste la labor cotidiana del virrey con sus escribanos y asesores se debe a que se trata de una actividad formativa propia del derecho provincial novohispano, con la producción de disposiciones llamadas "mandamientos". Estas acciones son asentadas en "libros de gobierno" por instrucciones reales ${ }^{15}$ a fin de poder ser consultadas por los virreyes sucesivos. Sin profundizar en el estudio específico de la figura del virrey - su origen y sus antecedentes -, es necesario subrayar que esta institución se relaciona con diferentes ámbitos de autoridad, ${ }^{16}$ dada la complejidad del orden en cuestión. Sin embargo, su articulación se legítima bajo la idea de la unicidad de la autoridad real del monarca. La autoridad del virrey ha sido sujeta, a lo largo del proceso de instauración - finalmente resuelto con la real cédula del 4 de julio de $1570^{17}$-, a una serie de contrapesos impuestos: por un lado, por la Corona y, por el otro, por las diferentes autoridades creadas en el territorio, donde el virrey es "cabeza del reino". En el proceso de consolidación de la institución virreinal, el papel fundamental lo juega la

${ }^{14}$ El término "ámbito" ha sido caracterizado por el doctor Andrés Lira González a lo largo de sus cursos en "historia de las instituciones políticas", en CEH, El Colegio de México, donde afirma que la visión histórica de los conceptos relativos a las diferentes autoridades políticas, religiosas, jurídica, fiscales, etc., no se pueden tratar como piezas encajonadas, más bien son conceptos, por sus naturalezas, dinámicos y por ende sus fronteras muy volubles. Así que es mejor usar un término que permita rendir la idea de tal dinámica.

15 “Instrucción a Luis de Velasco 16.IV.1550", cap. 40: Lewis Hanke, Los Virreyes españoles en América durante el gobierno de la Casa de Austria, México, vol. 1 (Madrid 1976), p. 142.

16 Autoridad entendida como ámbito de dominación legitima.

${ }^{17}$ Encinas, I, 244, en Ismael Sánchez Bella, Derecho Indiano, Estudios I. Las Visitas Generales en la América española, siglos XVI-XVII (Pamplona 1991), p. 567. 
acción cotidiana de ésta, a través de la oficina de gobernación, en donde su labor se inserta en la lógica del diálogo constante entre el proyecto de reino querido por la Corona y la realidad existente en Nueva España; el resultado a la postre será la creación de un sistema político en un territorio en expansión. En conclusión, la actividad cotidiana del virrey va definiendo sus competencias y funciones, es decir, su ámbito de autoridad.

Este fenómeno revela la formación de un derecho novohispano, a saber, un derecho originado en el territorio de la gobernación de Nueva España para Nueva España, que va a compenetrarse con lo que se identifica como derecho indiano. ${ }^{18}$ Los presupuestos que rigen tales afirmaciones se encuentran en la esencia misma de la institución virreinal: el virrey representa la autoridad del rey bajo la concepción de la monarquía, según la cual el principio rector es el "orden de justicia" como condición esencial para el "buen gobierno", es decir, dar a cada cual lo suyo y proteger y amparar al débil frente al fuerte. Dos instrumentos fundamentales para poder gobernar, la "prudencia" y la "justicia", están relacionados con esta visión y, de acuerdo con ella, el gobernante debía conocer bien la realidad con el fin de poder plasmarla y hacerla dialogar con la regulación general. El mismo Alonso de Zurita, en su Breve y sumaria relación de los señores de la Nueva España, producto de su experiencia como oidor y enmarcada en la visión jurídica de la época, subrayó la dificultad en la gobernación y costumbre de los naturales para dar regla general "porque casi en cada provincia hay diferencia en todo". ${ }^{19}$ A la larga, la percepción que los residentes de Nueva España se formaron acerca de cómo gobernar se

${ }^{18}$ Lo que a la larga se llamaría "derecho indiano" estaba integrado realmente por un abanico plural de normas jurídicas (reales cédulas, provisiones, instrucciones, ordenanzas, pragmáticas, etc.), dictadas por diversas autoridades, por lo cual adquirieron en conjunto el carácter de un ordenamiento casuístico y particularista. Las fuentes del derecho indiano fueron: legislación real, que recogía y ratificaba, por lo general, las disposiciones con que el virrey y la Audiencia iban dando la solución a problemas vivos de la colonia; reglamentación colonial dictada por el virrey o Audiencia para la aplicación de leyes reales o para llenar lagunas de estas; la jurisprudencia de los tribunales, del Consejo de Indias o Audiencias; las antiguas costumbres indígenas, mandadas a observar por la Real Cédula del 6 de agosto de 1555 , siempre y cuando no fueran contrarias a la religión católica ni a las leyes de la Corona; las nuevas costumbres y practicas indígenas. Al respecto véase Alfonso Caso/Silvio Zavala/José Miranda/Moisés González Navarro, La política indigenista en México, tomo I (2a ed., México, D.F. 1973), pp. 106-107.

19 Alonso de Zurita, Breve y Sumaria relación de los señores de la Nueva España (México, D.F. 1942), p. 77. 
redujo a la aplicación de normas que permitieron un buen gobierno y que apuntaron a resolver cada caso de acuerdo con las circunstancias concretas. La ley omnicomprensiva tuvo entonces una función diferente a la que se le atribuye hoy en día: era más bien una directriz de principios, tal como se puede desprender de la siguiente cita:

"[...] he hecho ordenanza sobre el vino y venta de negros [...] concerniente al buen gobierno de esta república. V.S. las verá y mandará guardar las que le pareciere que conviene, porque el tiempo y la variedad de las cosas hace que sea necesario cada dia quitar y añadir en ellas." ${ }^{20}$

Si bien esta afirmación, procedente de una ordenanza expedida por el virrey, puede llevar a suponer una menor fuerza respecto de las leyes y provisiones dadas por el rey, cuando se revisan provisiones dictadas por éste mismo se advierte que no fue así, pues estuvo de acuerdo en que era necesario actuar conforme a las exigencias de la realidad. Un buen ejemplo de esta postura lo ofrece la siguiente cita:

“[...] deseamos acertar en lo más sano [...] y por estar tan lejos y ser las cosas de dicha provincia tan diferentes de estos reinos [...] yo os mando [...] que proveáis todo lo que de presente o adelante se ofreciere o acaeciere aquello que viereis que más conviene para dichos fines y efectos, sin embargo de cualquier provisiones o instrucciones que por nosotros están dadas." 21

Este tipo de derogaciones derivó del principio de buen gobierno, que se asentaba en el orden inmanente de la naturaleza de las cosas, que no debía ser trastornado, y era, por lo tanto, perfectamente legítimo. La esencia del buen gobierno residía en el orden local, para el que se creaba y aplicaba la norma. De aquí surge la necesidad de analizar en este estudio los actos cotidianos del gobierno del virrey.

\section{EL MANDAMIENTO COMO ACTO PRODUCTOR DE DERECHO}

Este trabajo destaca el aspecto de la creación de un derecho factual a partir de las acciones cotidianas del virrey y no, precisamente, a través de las disposiciones de la Corona, ni tampoco de la doctrina ni de los principios generales de la jurisprudencia, predominantes en aquella

20 "Relación de Antonio de Mendoza a Luis de Velasco al término de su gobierno, sin fecha": Hanke, Los Virreyes (nota 15), pp. 44-45.

21 "Instrucción secreta a Antonio de Mendoza, 17 de abril de 1535", ibidem, pp. 31-32. 
época. En estas condiciones, el objetivo radica en evidenciar cómo la actividad consular reformatoria del virrey en su ámbito constituyó un precedente jurídico y, en sentido estricto, dio cauce a la jurisprudencia novohispana. Aquí se enmarcan los primeros lineamentos que dieron origen al derecho indiano novohispano a través de una caracterización formal de las disposiciones virreinales y sus definiciones.

\section{a) El mandamiento y sus características}

Se ha denominado mandamiento al cumplimiento de la función en todas sus competencias bajo el principio rector de buen gobierno, es decir, así se les llama a todos aquellos actos jurídicos cotidianos del virrey. Para poder identificar a un documento con esta designación, es primordial reconocer el significado jurídico del término mandamiento, así como las características originales que lo definían. Según Rafael Altamira, y de acuerdo con lo constatado en el curso de esta investigación, en las Leyes de Indias esta voz aludió a una forma de disposición derivada del empleo habitual de la fórmula "mando y ordeno", que se repetía en la mayoría de los preceptos promulgados. ${ }^{22}$ En los 14.971 mandamientos recopilados para esta investigación, se advierte que seguían el mismo formato, guiados por esta concepción:

El nombre del Virrey.

La causa del mandamiento.

El corpus del mandamiento con la formula: "os mando"; "os mando y ordeno"; "os ordeno" y por las licencias, mercedes, facultades y comisiones: "por la presente os doy ...".

El nombre del escribano y la fecha.

El proveído: síntesis al lado del documento escrito por el mismo escribano que indica el tipo de documento: "licencia a ..."; "merced de ... a ..."; "comisión a ..."; etcétera.

Más allá de los rasgos formales del mandamiento que son importantes para distinguirlo, no hay que perder de vista cómo se le ha definido:

"[Es un] testimonio escrito sobre un hecho de naturaleza jurídica, realizado bajo la observancia de ciertas y determinadas formalidades, variables según las circunstancias de lugar, tiempo, materia y persona destinadas a conferir a tal testimonio autoridad y fe, dándole fuerzas de prueba". ${ }^{23}$

22 Vocabulario recopilado por María Teresa Martínez Peñaloza/Archivo General de la Nación, Vocabulario de términos en documentos históricos (México, D.F. 1977), p. 42.

23 José Real Díaz, Estudio diplomático del documento indiano (Sevilla 1970), p. 3. 
Por ende, adquirió la connotación de un documento jurídico strictu sensu..$^{24}$ Así, el mandamiento fue un documento público, de acuerdo con la calidad y condición de la persona de quien procedía, como el virrey, y según su naturaleza y su contenido, que bien podía ser legislativo, gubernativo, judicial o hacendístico, entre otros más. Este documento jurídico, producido en el ámbito local, era equivalente, por un lado, a la real cédula emanada del rey e indicada por el Consejo cuando había sido emitido por el virrey en consejo con la Audiencia; por otro, se equiparaba con una real orden cuando sólo había sido dictado por el virrey (Tabla 1), en tanto que registraba preceptos de gobernación. Estos mandamientos reflejaban la labor del virrey y de su oficina de gobernación y fueron recopilados de manera consecutiva en los "libros de gobierno".

Los mandamientos, entendidos como actos jurídicos, ofrecen elementos para evaluar el grado de eficacia de un medio jurídico práctico con relación a la creación y el asentamiento de la estructura jurídica en una sociedad compuesta por diferentes grupos, ya que por este medio se sentaron las bases para la construcción de la autoridad real misma (en tanto expresada por el virrey). Asimismo, esta documentación permite analizar, en general, cómo se produjo la edificación de la autoridad virreinal con respecto al ámbito geográfico y a los grupos sociales existentes y, en particular, ayuda a identificar aquellas situaciones merecedoras de resoluciones inmediatas o mediatas que, a la postre, terminarían por tejer las relaciones entre los grupos sociales y las autoridades, en un constante reacomodo, resultante de la búsqueda de equilibrios de poder.

Con el mandamiento se hace referencia a una clase definida y concreta de documento, que sirve como una fuente válida para conseguir los objetivos del presente trabajo. Se han identificado dos tipos de mandamientos: los que expresaban la dirección explícita "A vos [...] corregidor[...]"; y los que pasaban inmediatamente a exponer la motivación y en los que aparecía, en forma constante, la expresión "por cuanto". 25

24 "Definición [...] inspirada en la que diera el Padre de la Diplomática moderna Teodor von Sickel en su Acta regum carolinorum .[...] - por ejemplo una real provisión, un mandamiento [...]": ibidem, p. 3.

25 Ibidem, p. 258. 
Entre los mandamientos existieron documentos de tipos probatorio y dispositivo. ${ }^{26}$ Este último expresaba un negocio jurídico que podía consistir, por ejemplo, en una orden para que se cumpliera algo. El mandamiento era firmado o refrendado por el escribano, quien podía ser de gobernación o de cámara (sin que se especificara su condición), y no tenía validación de sello real ni personal. Entre los mandamientos se encontraban las ordenanzas y los bandos. Las primeras registraban un conjunto de disposiciones para reglamentar, de un modo general, ya fuera una determinada materia o determinados asuntos, así como el ejercicio de cargos o las funciones de una institución. Por su parte, a los bandos se les designaba así por las circunstancias especiales en que eran publicados y por el objetivo que les regía, pues debían ser conocidos universalmente.

Es necesario describir detalladamente sus elementos técnicos para sustentar la validez de los documentos encontrados y revisados, sobre todo considerando que los tan citados "libros de gobierno", sugeridos por el virrey Mendoza a través de la relación hecha a Velasco y ordenados formalmente por el rey en $1550^{27}$ a este último, se encuentran dispersos y fragmentados.

\section{b) Sobre la sistematización de la información}

En cuanto a las acciones cotidianas del virrey, el número de documentos que se generó es muy elevado: la estimación hecha sobre la base de las series mensuales encontradas arroja una media de 60 mandamientos emitidos al mes, lo que significa que en 56 años (a excepción de los momentos en que otra institución desarrolló las funciones del virrey por ausencia) se produjeron cerca de 35.000 documentos. Los

${ }^{26}$ Tendremos documentos dispositivos (cuando la actio y conscriptio nacen simultáneamente) y los probatorios (cuando la actio ya es existente y simplemente el ponerlo por escrito tiene el fin de probar un hecho anterior y cumplido y del que es independiente: ibidem, p. 11.

27 En la Instrucción dada a Luis de Velasco, nombrado virrey de Nueva España, Valladolid, 16 de abril de 1550, se puede leer lo siguiente: "40. Asimismo Vos mandamos que de todo lo que proveyereis por vuestro mandamientos y otra cualquier manera quede registro dello[?] firmado del escribano que lo refrendare, lo cual asiente en un libro que mandéis hacer para el efecto porque es razón que haya registro de vuestro mandamientos como lo ha de haber de lo que proveyereis por nuestro título real y sello". Esta instrucción fue repetida en las demás instrucciones a los virreyes. Lewis Hanke/ Celso Rodríguez, Los virreyes españoles en América durante el gobierno de la Casa de Austria México, tomo I (Madrid 1976), p. 142. 
mandamientos recopilados durante el periodo en que se concentra este estudio y que comprende los gobiernos de los virreyes desde Mendoza hasta Velasco, hijo (noviembre 1535-noviembre 1595) son 14.971, cifra que, en proporción, representa $43 \%$ del total estimado. A propósito de este número y debido a que este estudio se funda, en un primer nivel, sobre un análisis cuantitativo, es conveniente indicar cómo se ha sistematizado la información. Se registraron los argumentos más frecuentes, o por lo menos aquellos que estuvieron presentes, de tal manera que todos aquellos temas que no tocaron los mandamientos son excluidos. Precisamente, para los fines de este trabajo se diseñó una base de datos por medio de la cual es posible tejer interpretaciones, extraer conclusiones y también reconstruir una visión de conjunto.

Los diferentes tipos de mandamientos se clasifican según la materia abordada y, aunque algunos de ellos pueden ser tanto breves como descriptivos, todos guardan una gran relevancia en tanto expresan un acto jurídico. Los argumentos comprendidos en el acto son los que justifican su emisión y la decisión contenida. Las variables se han definido de manera funcional, por lo que permiten una proyección de datos desagregados para una lectura más fácil.

\section{TABLA 1}

\begin{tabular}{l|l}
\hline Categoría & Comentario \\
\hline $\begin{array}{l}\text { Autoridad } \\
\text { Emisora }\end{array}$ & El Virrey o El Virrey en Real Acuerdo \\
\hline $\begin{array}{l}\text { Destinatario del } \\
\text { mandamiento }\end{array}$ & $\begin{array}{l}\text { La autoridad o el individuo a quien se delegaba la voluntad } \\
\text { jurídica del mandamiento (lo que se puede considerar como el } \\
\text { elemento de Intercessio, aunque no siempre de manera formal, } \\
\text { pero en todo caso eran todas aquellas terceras personas encargadas } \\
\text { de ejecutar la orden o de verificar la situación para informar } \\
\text { al virrey). En relación con este sujeto fue importante en este } \\
\text { estudio distinguir su calidad (indio, español, etc.), así como } \\
\text { el tipo de autoridad que representaba (alcalde, corregidor, etcé- } \\
\text { tera). }\end{array}$ \\
\hline $\begin{array}{l}\text { Sujeto del } \\
\text { mandamiento }\end{array}$ & $\begin{array}{l}\text { Cuando lo hubo, específica la autoridad o el individuo en quien } \\
\text { recaía la acción jurídica. También en esta categoría se decidió dis- } \\
\text { tinguir al sujeto por su calidad, el tipo y el nombre. }\end{array}$
\end{tabular}




\begin{tabular}{l|l}
\hline Categoría & Comentario \\
\hline $\begin{array}{l}\text { El lugar de acción } \\
\text { del mandamiento }\end{array}$ & $\begin{array}{l}\text { Esta categoría es la más delicada de todas, en tanto, como es bien } \\
\text { sabido, existen muchos lugares con el mismo nombre; por ende, es } \\
\text { necesario tener otros elementos de referencia como la autoridad } \\
\text { local, o la provincia o la doctrina, entre otros más, que no siempre } \\
\text { fueron especificados en los documentos. }\end{array}$ \\
\hline $\begin{array}{l}\text { El tipo de } \\
\text { mandamiento }\end{array}$ & $\begin{array}{l}\text { Es la caracterización más importante para los fines de nuestro aná- } \\
\text { lisis, y quizás la más difícil de identificar. }\end{array}$ \\
\hline $\begin{array}{l}\text { El objeto de } \\
\text { mandamiento }\end{array}$ & $\begin{array}{l}\text { Se relaciona directamente con el tipo de mandamiento y describe } \\
\text { al objeto. }\end{array}$ \\
\hline $\begin{array}{l}\text { Las causas } \\
\text { mandamientos }\end{array}$ & $\begin{array}{l}\text { Permite definir el origen de estos. A partir de esta variable se } \\
\text { puede determinar si respondían a problemas de orden "general" o } \\
\text { particular; si era una mera voluntad del virrey y sus consejeros a } \\
\text { fin de enderezar un proyecto, o si nació como resultado de conflic- } \\
\text { tos. En este punto es donde se valora el documento como probato- } \\
\text { rio o dispositivo. En especial fue importante verificar si existía una } \\
\text { súplica o una petición. La petición, como origen del mandamiento, } \\
\text { revela una situación anómala, la petición de requería una regla- } \\
\text { mentación. Es importante también identificar, en la medida de lo } \\
\text { posible, quién hizo la petición. }\end{array}$ \\
\hline
\end{tabular}

A la par que fue fundamental establecer las variables rectoras del análisis, fue necesario medir la frecuencia de los mandamientos recopilados a partir del número de documentos producidos.

Como se puede observar en la gráfica 1 resaltan dos picos: uno de ellos correspondiente al año de 1590, en que se expidieron 1.289 mandamientos, y el otro en 1591 con 2.581. Estos valores exceden el promedio considerado en la estimación general del número de mandamientos emitidos desde 1535 hasta 1595; sin embargo, los valores para los demás años se mantienen aproximadamente dentro de la previsión hecha. Cabe subrayar que no aparecen los datos correspondientes a $1535-1536,1539,1547,1558,1567-1568,1571-1572,1584$ y 1586-1588, debido a que en los expedientes revisados no se encontraron mandamientos de esos años. 


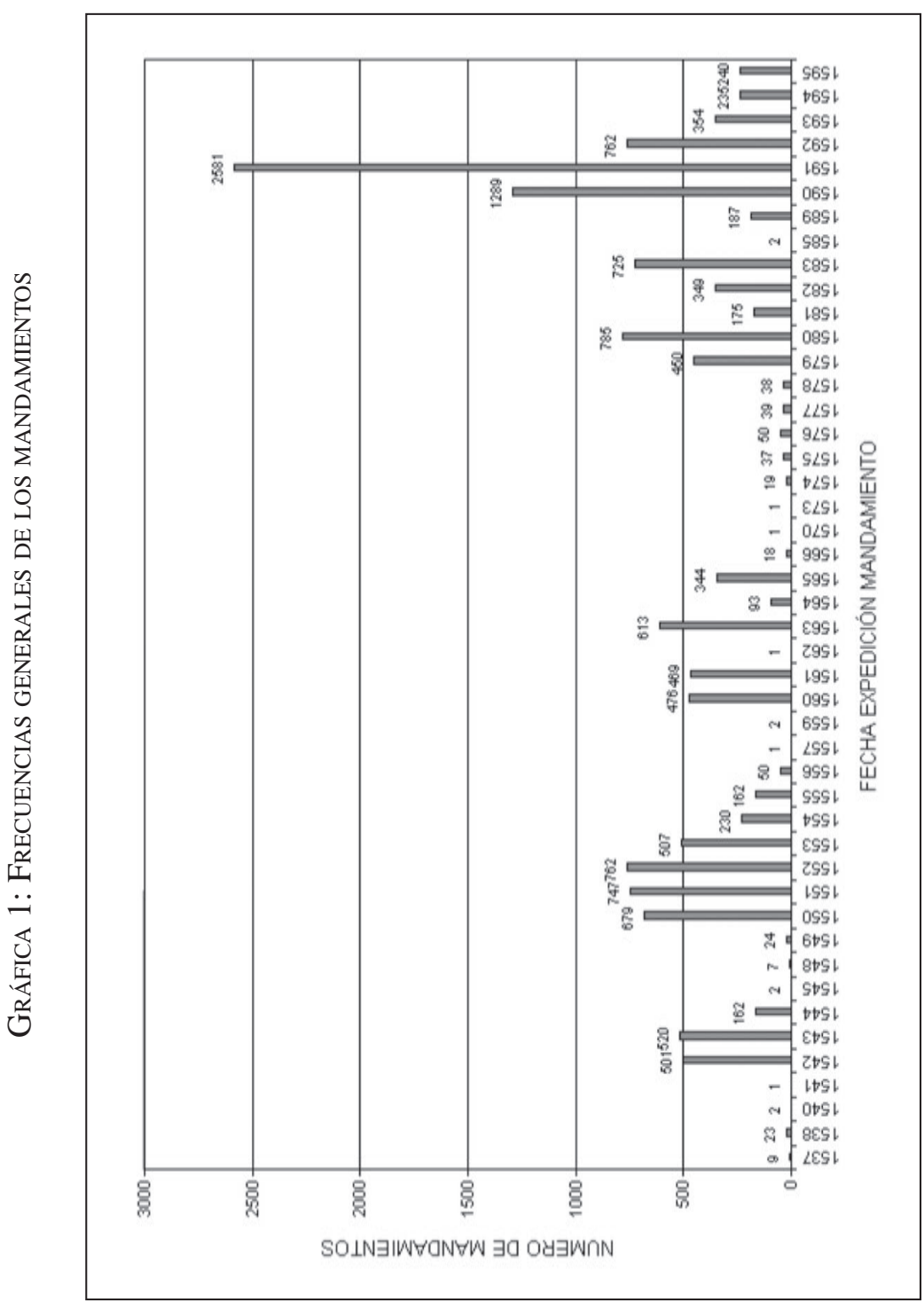


LOS MANDAMIENTOS Y LA DEFINICIÓN DE LAS COMPETENCIAS: LA CLASIFICACIÓN DE LA TIPOLOGÍA DE LOS DOCUMENTOS

Los mandamientos analizados revelan una gran actividad cotidiana del virrey. En ellos, las funciones ordinarias de gobierno, administrativa y jurisdiccional no siempre se identifican de manera clara y excluyente, lo que dificulta a veces una sistematización de los diferentes actos, debido a lo que era el concepto mismo del derecho.

Para los fines de este trabajo, se han dividido los actos en cuatro grandes grupos, de acuerdo con los enfoques cuantitativo y cualitativo del análisis de los mandamientos:

\section{1) Los actos exclusivos o privativos del virrey}

a. Son todos aquellos actos que por su naturaleza no debe delegar el virrey. El dictar ordenanzas, instrucciones, provisiones, prorrogar órdenes, el traslado y la publicación de órdenes reales, etc., que se pueden considerar como expedición de normas legales, lo que más se acerca a lo que hoy en día se conoce como la función legislativa.

b. Los actos específicos de la función de gobierno y judicial se dividen en ocho subgrupos:

b.1 El cumplimiento de órdenes (mandamientos que emite el virrey como ejecutor de una real orden o de una orden dada por una autoridad superior o con funciones diferentes del virrey).

b. 2 Las confirmaciones de órdenes (actos en virtud de los cuales el virrey confirma y avala una decisión o una disposición de otra autoridad. Pueden ser confirmaciones de mercedes de tierras, de nombramientos, de títulos, de instrucciones, de órdenes, etc.).

b.3 Las atribuciones de licencias y de facultades, que a veces pueden encontrarse juntas con la fórmula "licencia y facultad"; son documentos en los cuales el virrey atribuye una capacidad para hacer algo. Éstas cubren un vasto espectro de materias, desde el permiso de construcción de algo (que se puede considerar como merced) hasta las atribuciones de funciones por tiempo determinado o sobre hechos determinados (que se pueden considerar como delegaciones de poder). De hecho, aquí se destacan las licencias que atribuyen la "facultad para traer la vara de justicia", que entran directamente en la esfera jurisdiccional o gubernativa. 
b.4 Las atribuciones de encomiendas a través de su traspaso por herencia o por orden del rey.

b.5 Las atribuciones de mercedes, que también comprenden un vasto espectro de mandamientos, debido al significado jurídico del término, ${ }^{28}$ aquí se considera el otorgamiento de bienes como tierras, rentas, títulos.

b.6 La revocación de una concesión atribuida precedentemente.

b.7 Los nombramientos de autoridad.

b.8 Los amparos, que pueden ser de dos tipos: uno de "defendimiento real", acto de protección hacia un(os) individuo(s) - generalmente al indio del español - asumido por el virrey; el otro amparo como acto de protección hacía la posesión de un bien o de derechos al tiempo de desarrollarse un pleito o posesión de tierras. Esta función resulta que a veces se delega en su aplicación a una justicia menor.

\section{2) Los actos informativos del virrey}

Estos son funciones delegadas que no tienen ningún "rigor judicial"; sólo sirven para que el virrey se informe acerca del estado del gobierno en todas sus ramas, y para tomar medidas al fin del buen gobierno. Se trata, entonces, de acciones previas a las medidas jurídicas de diferentes materias. Comisiones informaciones pueden prever la existencia o ausencia de una relación. Estas cubren todas las materias existentes.

\section{3) Actos ejecutivos dictados por el virrey.}

En esta categoría caben todos los actos de la administración del virrey. Son actos que ejecutan una orden previa y a veces conllevan una petición de información sobre el estado de la cuestión que permita en determinado caso aplicar justicia. O simplemente son órdenes a las diferentes autoridades en diversas ramas del gobierno. Por ende, se consideran actos prevalentemente de carácter administrativo en los que se pide la ejecución de una orden previa.

${ }_{28}$ Según la definición del Vocabulario recopilado por Maria Teresa Martínez Peñaloza del Archivo General de la Nación, el término merced, aunque en las Siete Partidas se resalte la distinción entre mereced, misericordia y gracia, refiriéndose a tres acciones diferentes de la bondad del rey, en término general merced y gracia guardan cierta sinonimia y con ello se denomina el otorgamiento de un bien, tierra, renta, título nobiliario, etc., por parte del monarca o sus delegados autorizados. 
a. Orden: incluye actos que contienen órdenes explícitas de actuación hacía las diferentes materias y de diferentes competencias, que no tocan la esfera judicial. Éstas pueden tener carácter general o particular. La diferencia del carácter se identifica en la base de datos por la categoría "sujeto receptor". En ella se escribe para el caso general: "Todos"; si la orden es para las autoridades, se clasifica como "autoridad"; si es para todo el grupo social, se pone "colectivo" (sea o no corporación; en cualquier caso, se trata de particulares o de gobernados sin autoridad pública). La materia se identifica en el "objeto del mandamiento", por ejemplo tributo, tierra, quitas y vacaciones, etc. Son actos, sobre todo, que tratan materias de la Real hacienda y de la normal administración de gobierno, como la construcción de la infraestructura del país (calles, acueductos, puertos etc.). Aquí se pueden encontrar documentos que tratan de los tamemes, de la definición de tributos, de la moneda, etc.

b. Tasación: categoría que aparece alrededor de 1570; en esta recopilación de datos, el virrey atribuye a alguien, generalmente principales indios (gobernadores, caciques, alcaldes indios, regidores, etc...) una cantidad en bienes o trabajo de la parte india.

c. Comisión: Aquí se clasifican todos los actos que implican un intermediario en el desempeño de funciones que por lo general tratan de diferencias, que se supone entran en la esfera judicial. Hay comisiones, no obstante, que escapan de esta regla, como las comisiones para nombrar, que son relevantes por tener un peso político, e influyen en la construcción jurisdiccional del poder virreinal. En primer lugar, se tiene que subrayar un hecho sobresaliente con relación al concepto de delegación de funciones, ya que se han encontrado en los documentos dos tipos de comisiones: una que se puede llamar de facto en el sentido que se imparte una orden de averiguación o investigación, y sobre la base de ésta se ordena la aplicación del derecho; y otra en strictu sensu, en donde se atribuye la facultad con la fórmula "os doy poder cumplido". Según el análisis de estos mandamientos, resulta que la fórmula se aplica cuando la delegación se da a un individuo que no es corregidor ni alcalde mayor, por lo que se puede suponer que no tiene a su cargo la función de justicia. Y también se aplica a las dos autoridades antes mencionadas cuando la orden debe ejecutarse en un territorio que no corresponde a su jurisdicción territorial (comisión strictu sensu). 
d. Comisión determinación: Acto que es en su mayoría resultado de una averiguación precedente. Es una resolución de diferencias por parte de justicias según lo determinado por principio, o por ley ya asentada, o por un mandamiento del virrey. Son de dos tipos: orden de aplicación de justicia: cuando el virrey ordena la medida por aplicar o define la ley que se tiene que aplicar en el caso en cuestión; orden para hacer justicia: cuando el virrey otorga a una autoridad la facultad jurisdiccional de hacer justicia conforme a disposición previa.

\section{4) Actos de delegación de decisión.}

Son todos los mandamientos que delegan las funciones judiciales del virrey con poder de definición.

a. Hacer justicia: Término retomado por la fórmula jurídica utilizada en la época; significa delegar las funciones para solucionar diferencias, generalmente en casos concretos, y con el antecedente de una queja enviada al virrey; siempre implica una información previa a la solución.

b. Visita: Son actos que conceden facultades extensas al individuo encargado de la visita y se traslada la capacidad definitoria.

La interpretación y el análisis de las tipologías arriba descritas ha puesto al descubierto el papel de algunos mandamientos como indicadores de la instauración: en primer lugar de la autoridad virreinal; y en segundo como consecuencia del orden político de gobierno en el territorio novohispano. Estas disposiciones muestran conflictos con otras autoridades, a la par de consensos con algunas de ellas.

A la luz de la información obtenida, la delegación de funciones judiciales - o de influencia en el ámbito de la esfera judicial - que proporciona el virrey a los diferentes individuos o autoridades revela la existencia de conflictos en diferentes ámbitos, y es por ello que se pone particular atención en aquellos documentos descritos por las autoridade ${ }^{29}$ como comisiones o interpretados como tales. Estos mandamientos son indicadores de la voluntad de construcción de un orden del tipo de agente político requerido por el virrey en un terri-

${ }^{29}$ Esto es una referencia directa al "proveido" o "estracto" que se encuentra al lado del documento hecho por los diferentes escribanos como un índice descriptivo del documento. 
torio todavía no controlado por el gobierno virreinal. Al tiempo que las disposiciones dictadas en el ámbito de los actos ejecutivos del virrey - es decir, los actos propiamente administrativos, las órdenes son indicadores de la presencia de un orden de gobierno local reconocido por el virrey, muestran la presencia de interlocutores políticos formales del gobierno virreinal.

En el caso de la delegación de funciones en sentido estricto, el análisis muestra que ésta se da cuando en el mandamiento aparece la fórmula "os doy poder cumplido", lo que indica que el individuo encargado no tiene competencia propia, sino que la recibe del virrey. Esta puntualización, aunque puede parecer superflua, es fundamental desde el momento en que también se otorgan comisiones de averiguación y cumplimiento de orden a los corregidores ${ }^{30}$ y a los alcaldes mayores, ${ }^{31}$ y que justo en estos documentos no aparece la fórmula mencionada, pues aquellos sí tienen competencia y funciones judiciales en la esfera de la materia tratada, aunque no la tengan en el territorio en que se comisiona la indicación, es decir, la autoridad en referencia extiende sus funciones sobre un territorio que no es, en principio, parte de su jurisdicción local. Lo anterior permite ver cómo se está vinculando, en un primer momento, el poder de las autoridades al

${ }^{30}$ Los corregidores eran jueces locales. Su establecimiento correspondió a la Segunda Audiencia (1531). En 1530 se dieron varias instrucciones reales en donde: primero, se establecieron corregidores encargados de proteger a los indios contra los abusos de los encomenderos y sus calpisque o mayordomos, y especialmente de doctrinarlos en la fe católica; segundo se mandó quitar los indios encomendados de forma irregular por la Primera Audiencia y que estos pueblos libres fueran gobernados por corregidores y al final de su mandado anual darían residencia. Reales Instrucciones a los corregidores de Nueva España y capítulo de los Gobernadores en Indias, Madrid, 12 de julio de 1530. V. de Puga, Provisiones, Cedulas Instrucciones para el gobierno de la Nueva España (ed. facs., Madrid 1945), fs. 52-56v. Real Instrucción a la Audiencia de México, 1530: Diego de Encinas, Cedulario Indiano, L. 3, fol. 17. María Justina Sarabia Viejo, Don Luis de Velasco Virrey de Nueva España 1550-1564 (Sevilla 1978), p. 64.

${ }^{31}$ Los alcaldes mayores o justicias mayores eran jueces provinciales. Este cargo se introdujo en tiempos de Hernán Cortés, estableciéndose alcaldías mayores en las villas con cabildo español que dependían del rey, principalmente en los puertos y mineras. Se diferencian de los corregidores porque eran de provisión real y nombrados interinamente por el virrey; eran jueces de segunda instancia, aunque podían llegar a conocer la primera; sus atribuciones correspondían a la esfera provincial en la que también actuaban como jueces de apelación de los alcaldes ordinarios en materia civil; recibían comisiones por tareas gobernativas, militares y hacendísticas. Presidían el cabildo, pero no ex oficio como los corregidores sino por su dignidad superior, y no cobraban sueldo fijos. Ibidem, pp. 61-62. 
ámbito geográfico, elemento que encaja perfectamente con el recorrido histórico de los principios del derecho, y que es expresión del asentamiento del Estado moderno.

El hecho de que el virrey pida información o averiguación de un hecho a una autoridad local sugiere que existe una situación anómala o, al menos, la voluntad de conocer la realidad para normarla. En una situación irregular los mandamientos se dan para que los actores cumplan lo que prevé la ley, ya sea porque no lo están cumpliendo, o porque no están al tanto de los problemas o circunstancias que dieron lugar a la queja, enviada o presentada directamente al virrey por los individuos particulares. Esto lleva a pensar, por un lado, en una posible desconfianza en los jueces locales y provinciales por parte de los quejosos, pero también en la creencia de que el único interlocutor directo del rey, titular de toda la autoridad en el sentido paternal, es el virrey.

Las comisiones en los mandamientos se dan con relación a casos específicos de quejas, de los que ha sido informado el virrey a través de relaciones. Pero, respecto a los casos generales, el análisis ha permitido identificar otro sistema de delegación o comisiones, que se dan con las licencias y facultades - o con la licencia nada más para traer vara de justicia - y con los nombramientos. Resulta que en las licencias no se define el tiempo de uso de la función, ni si ésta termina con la solución del problema específico.

Anteriormente se ha ilustrado de qué tipo pueden ser las disposiciones del virrey según sus diferentes ámbitos de funciones; aquí se sintetizan en una "leyenda" que permita facilitar la manipulación de los datos y, por ende, su interpretación. A estos grupos de mandamientos muchas veces se agregan sub-categorías para identificarlos de manera específica pero que aquí se omiten, remitiendo esta información a un trabajo sucesivo. 
Tabla 2: Frecuencia cumulativa de las categorías de los MANDAMIENTOS 1535-1595

\begin{tabular}{l|r|r|r|r|r|r|r|r|r|r|r|r}
\hline & 1540 & 1545 & 1550 & 1555 & 1560 & 1565 & 1570 & 1575 & 1580 & 1585 & 1590 & 1595 \\
\hline Amparo & 0 & 12 & 38 & 108 & 9 & 50 & 0 & 0 & 4 & 6 & 24 & 206 \\
Asenta- & 0 & 8 & 0 & 0 & 0 & 0 & 0 & 0 & 0 & 0 & 0 & 0 \\
miento & 0 & 0 & 0 & 0 & 0 & 0 & 0 & 0 & 0 & 0 & 0 & 49 \\
Autos & 0 & & & & & & & & & & & \\
posesión & & 187 & 147 & 397 & 54 & 202 & 1 & 1 & 205 & 114 & 181 & 452 \\
Comisiones & 6 & 30 & 9 & 27 & 3 & 4 & 0 & 0 & 0 & 0 & 0 & 0 \\
Encomienda & 4 & 18 & 86 & 30 & 74 & 1 & 2 & 40 & 51 & 91 & 217 \\
Expedición & 1 & 64 & 18 & & & & & & \\
norma & & & & & & & & & & & \\
Facultad & 0 & 3 & 1 & 3 & 10 & 9 & 0 & 1 & 0 & 0 & 2 & 17 \\
Licencias & 7 & 177 & 126 & 550 & 54 & 100 & 1 & 2 & 249 & 268 & 213 & 689 \\
Mercedes & 3 & 285 & 94 & 315 & 164 & 138 & 13 & 0 & 2 & 2 & 0 & 3 \\
Nombra- & 0 & 74 & 44 & 126 & 10 & 25 & 0 & 0 & 39 & 36 & 22 & 118 \\
mientos & & & & & & & & & & & & \\
Órdenes & 13 & 320 & 220 & 778 & 194 & 390 & 3 & 6 & 616 & 676 & 924 & 2373 \\
Tasaciones & 0 & 1 & 0 & 0 & 0 & 2 & 0 & 42 & 170 & 59 & 0 & 1 \\
\hline
\end{tabular}

La gráfica general muestra que la mayoría de los mandamientos son del tipo "orden", "licencia" o "merced", que indican las acciones ordinarias de la gobernación en su cotidianeidad, además de que las mercedes y las licencias son las acciones predominantes en la primera época del asentamiento de la autoridad española. Esto confirma la validez de la documentación encontrada y la confiabilidad de los datos.

\section{Algunos Resultados CONCRETOS DE LA INVESTIGACión SOBRE LOS TIPOS DE MANDAMIENTOS}

La clasificación de los mandamientos descubre las tendencias en la expedición de estos durante un periodo de larga duración, entre otras cosas gracias a un análisis cuantitativo. Si a éste se agrega un examen cualitativo de las diferentes variables involucradas en las disposiciones (agente receptor, lugar de actuación, tipo de delegación de funciones, etc.), entonces los mandamientos revelan la gradual construcción de los mecanismos de poder del virrey, la articulación de los diferentes actores políticos y la gestación de los grupos de poder en el ámbito del gobierno novohispano. 
Anteriormente hemos analizado la gráfica de expedición de mandamientos a lo largo del periodo bajo estudio. Esos números han permitido identificar las tendencias de estas disposiciones, lo que abre la posibilidad a todo un abanico de interpretaciones históricas de tales fenómenos.

GRÁFICA 2: COMPORTAMIENTO DE LA FRECUENCIA DE LOS TIPOS DE MANDAMIENTOS 1535-1595

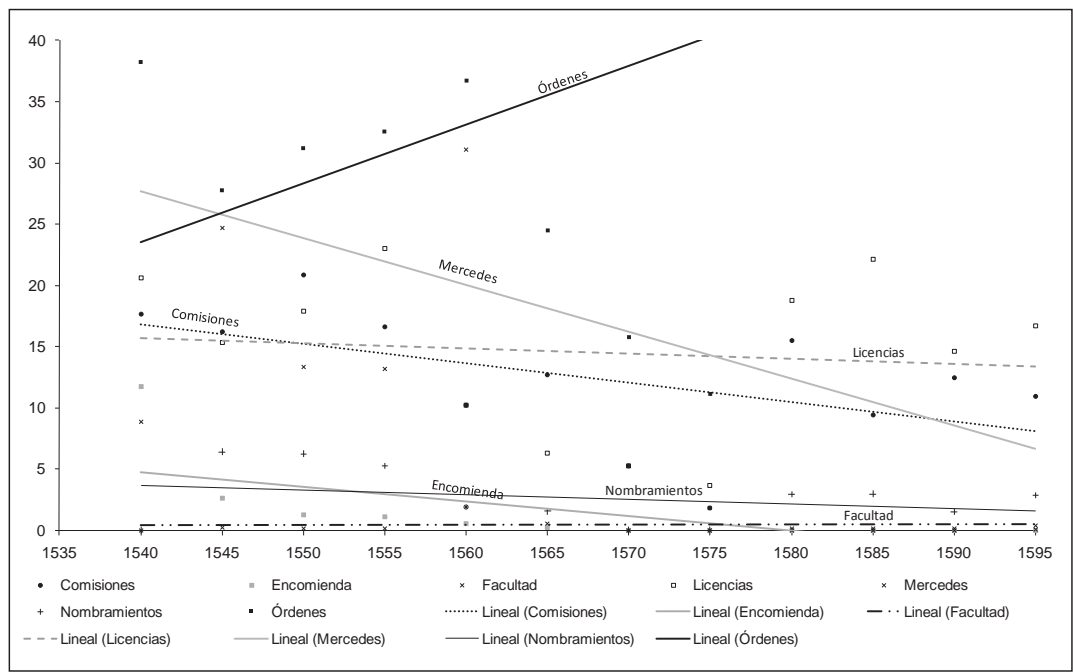

Una primera aproximación al análisis de la gráfica anterior muestra que las disposiciones del tipo "encomienda" desaparecen alrededor del año 1580, algo que puede interpretarse como que la cuestión de las encomiendas desaparece de las funciones de gobierno del virrey, como lo confirman los vastos estudios históricos existentes sobre este tema. Las disposiciones de tipo "mercedes", relativas a la concesión de títulos de tierras, disminuyen de manera sensible por una parte debido a que tal competencia ya es compartida por diferentes instituciones como los cabildos y, por la otra, debido a que las cuestiones de la tierra y sus posibles atribuciones están sujetas a otro tipo de controles. En parte ya han sido concedidas y su papel empieza a ser marginal en la función de gobierno del virrey. Otros bloques de mandamientos, como los "amparos", "licencias", "facultad" o "expedición de norma", 
tienen cambios poco notables, lo que revela que son competencias efectivas del virrey y sus variaciones dependen más de los mecanismos sociales y políticos. Entre estas disposiciones se encuentran algunas de particular interés que identifican y justifican la hipótesis de este trabajo, que sólo busca hacer énfasis en aquellas variables que resaltan la consolidación del modelo de gobierno virreinal a través de sus disposiciones, como evidencia del proceso de formación del derecho novohispano en el devenir histórico de un país. Esas disposiciones son las "comisiones" y las "órdenes", cuya evolución revela el grado de instauración del modelo de gobierno ibérico en Nueva España.

Las comisiones, a las que se dedica un capítulo entero en mi tesis doctoral, ${ }^{32}$ son una categoría que comprende diferentes tipos de disposiciones y que, desglosadas en sus modelos, muestran las materias de competencia del virrey, el poder de delegación de éste en un ámbito jurisdiccional, los conflictos existentes con los diferentes grupos sociales y los agentes políticos existentes de facto o constituidos en Nueva España. Pero lo más importante es que representan, por su naturaleza, un indicador de la falta de orden por parte del gobierno novohispano ${ }^{33}$ en el territorio al que se envía la delegación de la función del ámbito jurisdiccional.

Según la perspectiva expuesta, es necesario identificar el tipo de mandamiento que, en respuesta, representa el indicador de la presencia de un orden, y éste es el de las "órdenes". Se trata, también, de una categoría general que comprende diferentes tipos de disposiciones, tales como las arriba mencionadas, pero que, en contraste con las comisiones, muestra la existencia del aparato de gobierno local en funciones. A la par que las comisiones, las órdenes descubren a los agentes de gobierno en sus tareas ordinarias como interlocutores directos del virrey, las materias de competencia de estos, las relaciones entre los diferentes grupos sociales y, finalmente, el grado de control del territorio; así que la evolución de estas dos categorías en un periodo de larga duración arroja una tendencia decreciente de las comisiones y un aumento de las órdenes, lo que representa una evidencia de la consolidación de la autoridad virreinal y de la articula-

${ }^{32}$ Semboloni, La construcción de la autoridad virreinal (nota *), cap. 2.

${ }_{33}$ Con orden de gobierno novohispano me refiero a la instauración del sistema dictado por la Corona en el Virreinato de Nueva España, omitiendo voluntariamente el término "colonial" que no es adecuado, considerado que estos territorios, en su clasificacion juridica, no eran colonias sino "reinos". 
ción de ésta en el territorio. Para sustentar esta afirmación se muestra la gráfica de tendencias de estas dos categorías, desglosada de la gráfica general.

TENDENCIA DE LA FRECUENCIA DE LAS ÓRDENES Y LAS COMISIONES: $1535-1595$

Hasta aquí se han mostrado sólo algunos resultados del espectro de posibles interpretaciones que permite este tipo de estudio. Para concluir y dejar abiertas algunas preguntas, se muestra ahora que el análisis de los mandamientos con relación al "sujeto receptor", en una lógica de gobierno indirecto según la cual se otorgan derechos y deberes diferenciados a los diferentes estamentos presentes en el territorio novohispano, ${ }^{34}$ permite identificar los grupos políticos y sus mecanismos de reproducción en la sociedad. De acuerdo con la variable "sujeto receptor", las disposiciones dictadas por el virrey a lo largo de los 60 años manifiestan quiénes eran sus interlocutores directos y los cambios de estos en sus funciones de gobierno, divididos según las calidades "español" o "indio" (sin profundizar aquí en el análisis de esta variable, vale mencionar tan sólo que es la que contiene el mismo documento).

${ }^{34}$ Marcello Carmagnani, El otro Occidente. América Latina desde la invasión europea hasta la globalización (México, D.F. 2004), pp. 56 y ss; y Carmagnani, "El virrey y la Corte virreinal" (nota 2). 
GRÁFICA 3: TENDENCIA DE LA FRECUENCIA DE EXPEDICIÓN DE MANDAMIENTOS RESPECTO AL ALCALDE MAYOR, CORREGIDOR Y ENCOMENDERO,

$1535-1595$

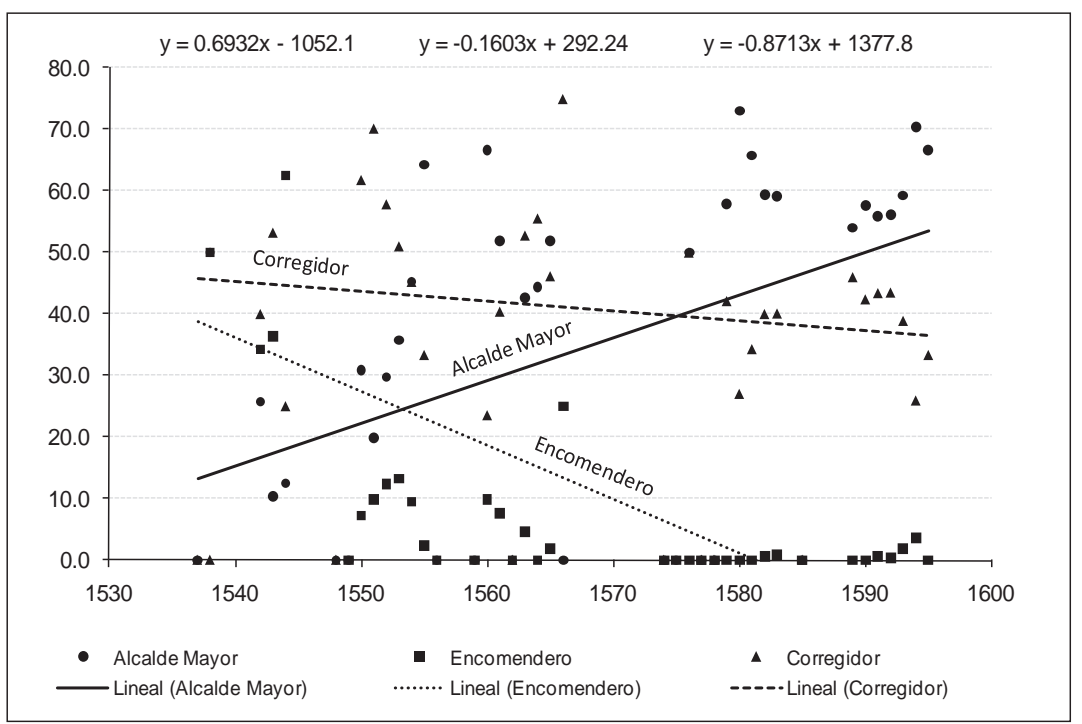

Con relación a lo que responde como calidad "española", la gráfica muestra que después de 1566 se da un cambio de tendencia entre las figuras de alcalde mayor y de corregidor, es decir, hasta aquel año el actor preferido por el virrey era el corregidor. Respecto al tipo de mandamientos, la menor cantidad de delegación de funciones para el corregidor y para el alcalde mayor, entre los años 1566 y 1595, se debe a un creciente control del territorio y a una más clara división de jurisdicciones en el ámbito territorial. Este resultado evidencia que el alcalde mayor no sólo no ha desaparecido al final del siglo XVI, sino que más bien asume relevancia, y tiene funciones y competencias específicas y diferentes del cargo de corregidor.

Con relación a la calidad "indios", la gráfica anterior muestra un cambio de tendencia entre las figuras del gobernador y del principal después de 1566. Mientras que en las primeras décadas el actor más solicitado por el virrey es el principal, después llega a ser el gobernador, lo que define el canal directo con el gobierno virreinal y, a la postre, el asentamiento del orden novohispano. 
GráFICA 4: TENDENCIA DE LA FRECUENCIA DE EXPEDICIÓN DE MANDAMIENTOS DE LAS FIGURAS: PUEBLO INDIO, GOBERNADOR, PRINCIPAL Y CACIQUE $1535-1595$

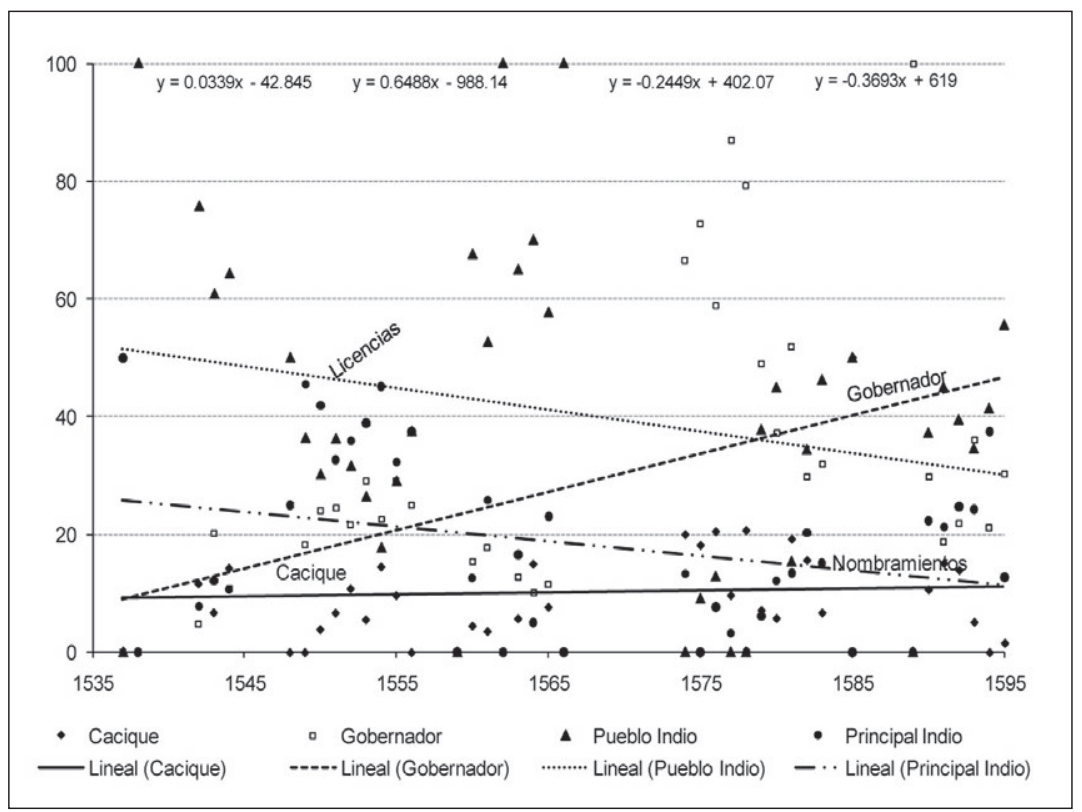

Finalmente, el estudio de los mandamientos muestra que, alrededor de 1590 , el sistema político novohispano ya se ha asentado en el territorio con la determinación de las dos repúblicas: la de indios y la de españoles. El estudio arroja también como resultado que los interlocutores directos del virrey - en la lógica del sistema de gobierno - son, por la república de españoles, el alcalde mayor y, por la república de indios, el gobernador. Estos cargos revelan que, en la articulación del ámbito de la autoridad política del Virreinato, se ha logrado sustituir a aquellas autoridades con títulos tradicionales (encomenderos y caciques) por otros cargos funcionales propios del aparato de gobierno (alcalde mayor y gobernador). De aquí surge la siguiente pregunta: ¿Ha modificado la definición de estas autoridades los mecanismos de reproducción social entre los grupos de poder? En otras palabras, ¿ha desplazado este orden político-formal el orden tradicional?

El estudio de las disposiciones del virrey ha evidenciado la formación de un derecho específico para Nueva España, lo que permite 
conocer más a fondo su realidad; pero esto es sólo una pequeña parte del gran horizonte de investigación por realizar, ya que el orden de la sociedad novohispana es un tejido de diferentes ámbitos de autoridades que actuaban a través de disposiciones, como los cabildos civiles y eclesiásticos, las Audiencias, las capitanías, etc. Estas disposiciones o decisiones como praxis en su nivel local - lo que se refleja en los mecanismos de articulación y reproducción de la sociedad misma - no se pueden pasar por alto. 